\title{
Testing of a Low-Cost Loop Heat Pipe Design
}

\author{
Cosimo Buffone \\ Microgravity Research Centre, Universitè Libre de Bruxelles, Bruxelles, Belgium \\ Email: cbuffone@ulb.ac.be
}

Received 17 January 2014; revised 17 February 2014; accepted 24 February 2014

Copyright (c) 2014 by author and Scientific Research Publishing Inc.

This work is licensed under the Creative Commons Attribution International License (CC BY).

http://creativecommons.org/licenses/by/4.0/

(c) (i) Open Access

\section{Abstract}

This paper presents and describes the test campaign of a low-cost Loop Heat Pipes (LHP) design. LHP have been around for many decades now. Their potential as passive heat transfer devices has been widely demonstrated in numerous both ground- and space-based applications. One of the major disadvantages of LHP is their inherent high manufacturing cost; this is the main factor why LHP are still confined to niche/high end applications such as thermal management of spacecrafts. This paper proposes to use an alternative manufacturing design for the LHP evaporator, which is the main contributor to the overall LHP cost. Preliminary thermal results are also reported and briefly explained. Future work is needed to confirm the promising results discussed in this paper and address fully other issues such as tolerance of this LHP design to vibrations and accelerations typical of space missions.

\section{Keywords}

\section{Loop Heat Pipe; Low Cost Evaporator}

\section{Introduction}

Loop Heat Pipes (LHP) were firstly conceived in Russia in the mid 70's to address some of the heat transfer issues present on board spacecrafts [1]-[7]. One of the main issues in spacecrafts such as satellites is their long-life span, typically of the order of many years (stretching to over 2 - 3 decades as well). For this reason, passive solutions are generally preferred to active ones because of the inherent reliability and life issues problems associated with active components such as pumps.

LHP are basically completely passive heat transfer devices which are able to transfer heat between two (or more) remote locations which are kept at different temperatures [8]-[12]. LHP have been around for many decades and have been successfully tested in numerous applications, both ground and space ones. LHP are suitable for low $(>20 \mathrm{~W})$ and high $(>12 \mathrm{~kW})$ heat loads and can operate at low $\left(-160^{\circ} \mathrm{C}\right)$ and high $\left(>200^{\circ} \mathrm{C}\right)$ temperatures. LHP are not so much different from the basic Heat Pipe (HP) concept, and therefore as Heat Pipes they are very 
versatile. However, LHP are far superior to standard HP because the wick is only present in the evaporator section (which is typically a very small proportion of the overall LHP length), and they have separate liquid and vapour lines connecting the evaporator and the condenser. These factors allow the use of very fine powders to produce high-performing sintered wicks (typically Nickel or Titanium), and also remove the entrainment limitation due to counter-flowing liquid and vapour in intimate contact as in standard HP designs.

LHP design has changed very little over so many years. In particular, the evaporator layout is basically the same as it was invented in the late 70's. One of the main reasons why this fact has stood well the test of time is that LHP are very difficult heat transfer devices to predict. In particular, the evaporator is a very complicated part to predict: the primary wick is an intricate porous media inside which two-phase with phase change takes place; the complex network of vapour removal grooves on the primary wick outside surface and the associated heat and mass transfer inside the grooves makes it difficult to predict the hydro-thermal dynamics; the complex thermal coupling of the evaporator with the compensation chamber (liquid reservoir) makes the thermal control of LHP quite challenging. Several detailed studies have described different modelling strategies to predict LHP performance [13]-[15].

Almost in parallel and independently from the invention of LHP, the Americans at NASA had conceived the Capillary Pumped Loop (CPL) [16]. CPL is very similar to LHP and their operational principle is fundamentally the same. CPL has the liquid reservoir remotely located from the evaporator. This is a fundamental difference as it allows the evaporator to be very small and fit on confined spaces where there are packaging issues. The remoteness of the liquid reservoir also allows the adoption of multiple evaporator designs as one single liquid reservoir can feed all the evaporators. The remoteness of the liquid reservoir allows for independent temperature control of the CPL by setting up the liquid reservoir temperature; that is why CPLs are referred as loops with cold-biased reservoir. This fact gives CPL a very fine temperature tuning capability which is by far superior to LHP designs. Typically CPL temperature can be controlled within $\pm 1^{\circ} \mathrm{C}$ accuracy. However, CPL has a major issue with the evaporator priming at start-up. In fact, because there is no mechanical connection between the evaporator and liquid reservoir, it is likely that most of the liquid is inside the liquid reservoir instead of the evaporator; therefore, at start-up one must ensure that the CPL evaporator is primed before heat is applied to it. The evaporator priming is a very long and tedious procedure (can take between $30 \mathrm{~min}$ and a few hours). For this reason CPLs are typically not preferred to LHP; and only when LHP cannot be used because of their limitations, CPL should be chosen instead.

Several studies have also been published on miniature LHP [17]-[19] and high performance wicks [20] [21] in which it has been proven that LHP can easily been scaled down maintaining its superior thermal performance and wicks can be designed to improve performance of the evaporator.

One of the major problems with LHP is the manufacturing and assembling cost of the evaporator. The typical manufacturing steps of a LHP evaporator are: 1) powder sintering to produce the primary wick; 2) creation of the network of grooves on the wick outside surface; 3) insertion of the wick inside a heated metal jacket; 4) the integration of the compensation chamber with the evaporator by using the secondary wick and at times the bayonet. The creation of the network of grooves and the insertion of the evaporator inside the metal jacket are the most difficult steps which typically result in high scraps rates because of damage on the grooves.

Recent attempts to reduce the manufacturing cost of LHP have started appearing in the open literature [22] [23]. Much more is been done, but given the commercial potentials of these attempts, still few of these studies are published.

The present work suggests a different way of manufacturing LHP evaporators. It is proposed that only longitudinal grooves are created during the sintering process by the insertion of mandrels in intimate contact with the metal jacket. The metal powder is therefore sintered inside the metal jacket. This allows at once the complete removal of the groove creation and wick insertion inside the metal jacket after the sintering process. Therefore, manufacturing costs should be dramatically reduced; even the scrap rate should be significantly improved.

Copper powder with average pore size of $10 \mu \mathrm{m}$ is used and 8 stainless steel mandrels (vapour removal channels) with ID of $2 \mathrm{~mm}$ are used. The jacket material is copper with $2.5 \mathrm{~mm}$ thickness. The mandrels are secured in contact with the internal surface of the jacket through the use of a specifically designed jig. The copper powder is introduced inside the jacket and subsequently pressed up to $250 \mathrm{MPa}$. The subsequent sintering process took place in a furnace with controlled atmosphere at a temperature of $850^{\circ} \mathrm{C}$ for 2 hours.

The manufacturing process of the wick is slightly different from the process described in a previous relevant work by Vasiliev et al. [24] where a "chemically active substance" is used for Nickel powder in order to avoid 
important shrinkage inside of the wick during sintering.

The drawback of such a design is that there are no circumferential grooves on the primary wick which may create circumferential temperature differences when heat is applied only to one side of the LHP evaporator. This penalty may be alleviated by the use of thicker metal jackets which should conduct more heat around the circumference. However, this results in larger thermal resistances of the evaporator. Much more work is clearly needed to see if this issue can be addressed.

\section{Preliminary Thermal Test Results and Discussion}

In this section some preliminary thermal tests performed on the low-cost LHP design with water as working fluid are presented and briefly discussed.

Figure 1 shows a not to scale schematic of the low-cost LHP with the thermocouple location. Dimensions of LHP parts are also given in millimetres in the same Figure 1. The evaporator, compensation chamber, condenser, liquid and vapour lines are also indicated in Figure 1. As can be seen from Figure 1, both the liquid and vapour lines have flexible parts (the tubes are basically coiled) that allow the rotation of the LHP condenser with respect to the evaporator.

A wire heater was wrapped around the evaporator sector and the total power delivered by the heater was controlled via a variac. Insulation was provided around the heater to limit the heat losses versus the ambient.

Figure 2 reports the LHP response at power ramp-up and down. Power (which is also reported in Figure 2 as the step-wise black curve) is varied between 0 and $100 \mathrm{~W}$ in successive steps after steady state readings were achieved with the thermocouples. Additionally, in Figure 2 for completeness also the ambient temperature (thermocouple number 8) was monitored during tests.

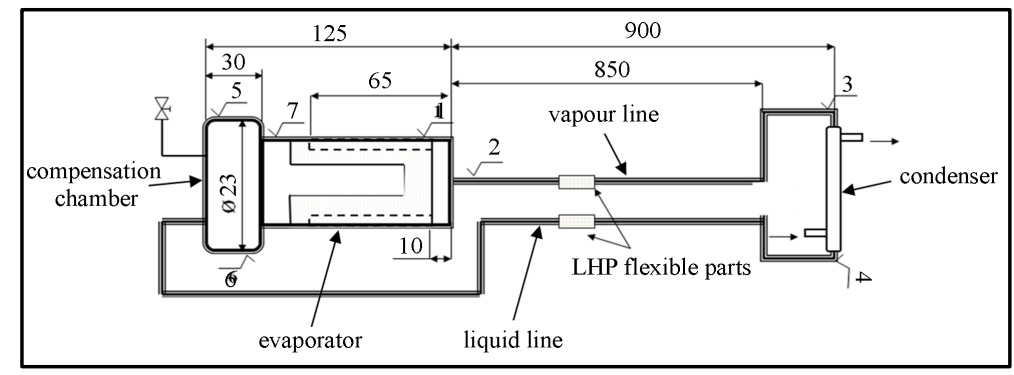

Figure 1. Schematic of loop heat pipe. 1 - 7 are K-Type thermocouples. All sizes are given in millimeters.

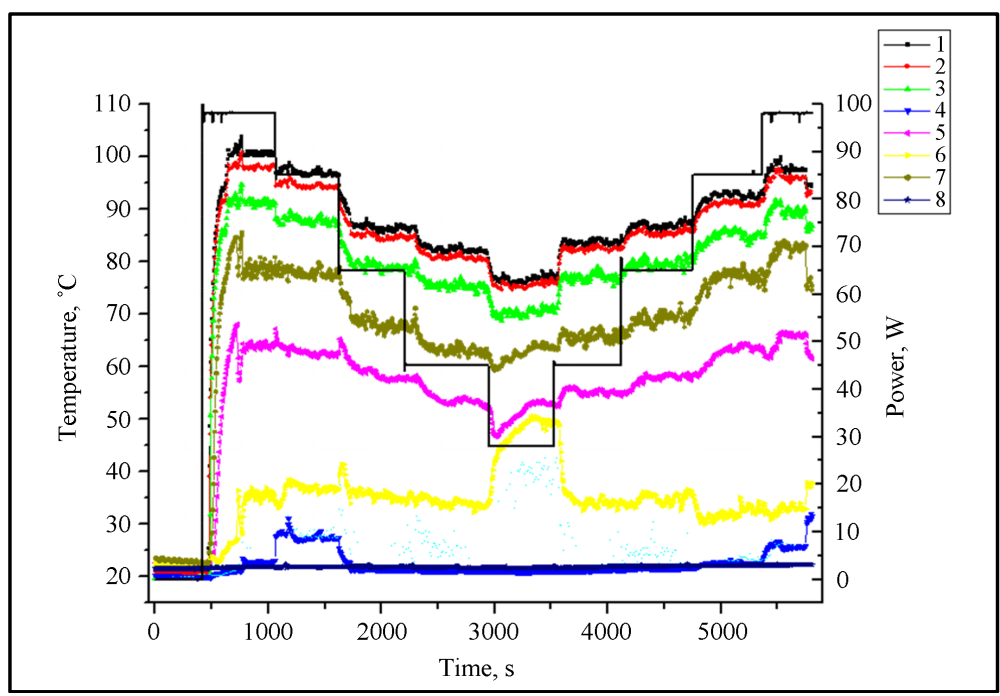

Figure 2. Power ramp-up and down. Power applied is given by the step-wise black curve. Thermocouple number 8 measures the ambient temperature. 
As can be seen from Figure 2 after the first power setting (100 W) was applied there is significant temperature raise in all but thermocouple 4, and a small but distinct temperature over-shoot which is necessary to displace all vapour bubbles inside the primary wick at start-up. The response of the LHP is around $200 \mathrm{~s}$ which is relatively large; this is believed to be due to the small diameter of the vapour line. Subsequently, the low-cost LHP design responds quite well at input power changes.

Power cycling tests have also been performed and they are presented in Figures 3 and 4. In Figure 3 power is changed between two set values (20 and $60 \mathrm{~W}$ ). The LHP responsiveness is very good indeed over 1 hour of operation. In Figure 4 the power has been varied between two levels ( 45 and $90 \mathrm{~W}$ ) for the first two cycles and for successive cycles the power has also been taken down to nil value. Again, the response of the LHP is good over around 40 minutes of operation.

In Figure 5 for a fixed power setting $(85 \mathrm{~W}$ ) the condenser temperature has been varied and the evaporator temperature monitored. It can be clearly seen that there is a quasi-linear relationship between the evaporator and condenser temperatures. There are two typical LHP operational modes, namely: constant conductance and variable conductance [10]. Inspection of Figure 5 suggests that the LHP is working in its constant conductance mode (where the equivalent thermal conductivity of the LHP is constant as in a normally functioning Heat Pipe).

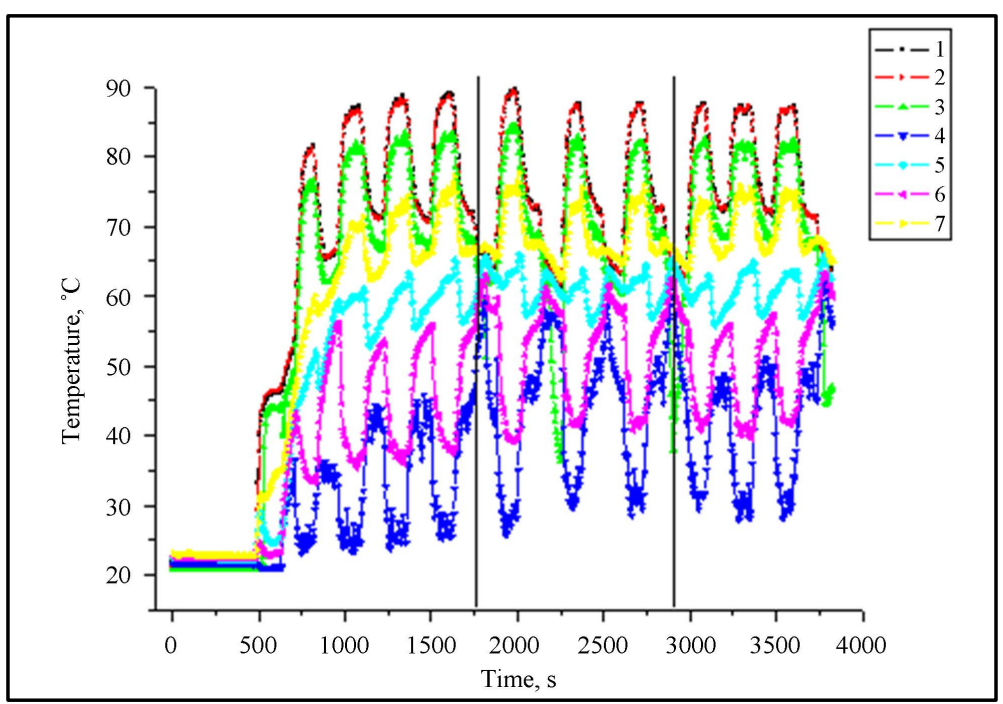

Figure 3. LHP response to power cycling between 20 and $60 \mathrm{~W}$.

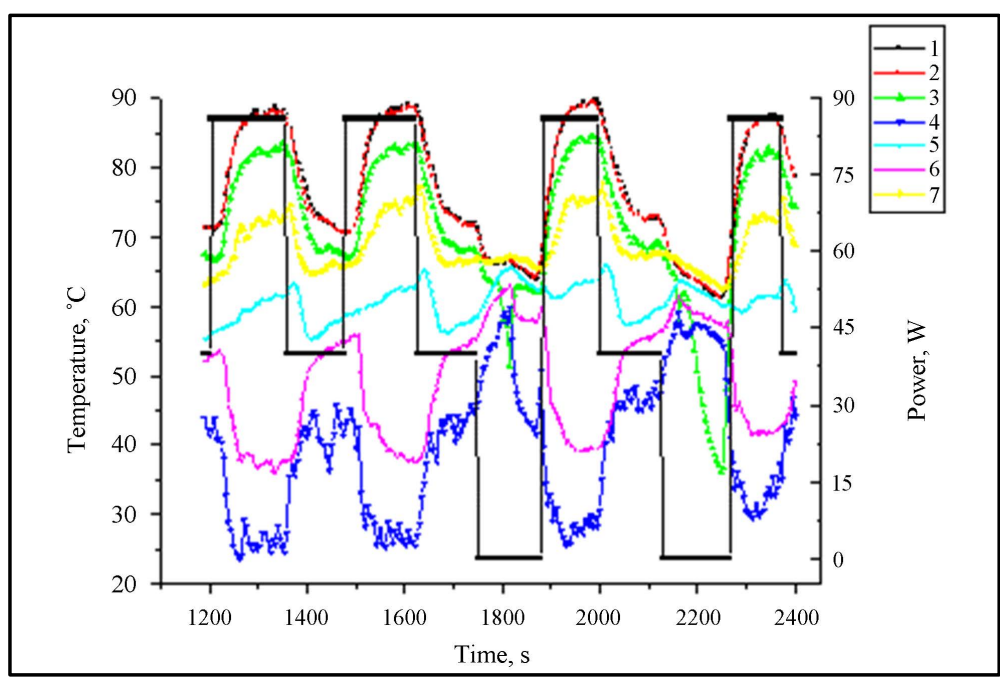

Figure 4. LHP response to power cycling between three power levels $(0,45$ and $90 \mathrm{~W})$. 


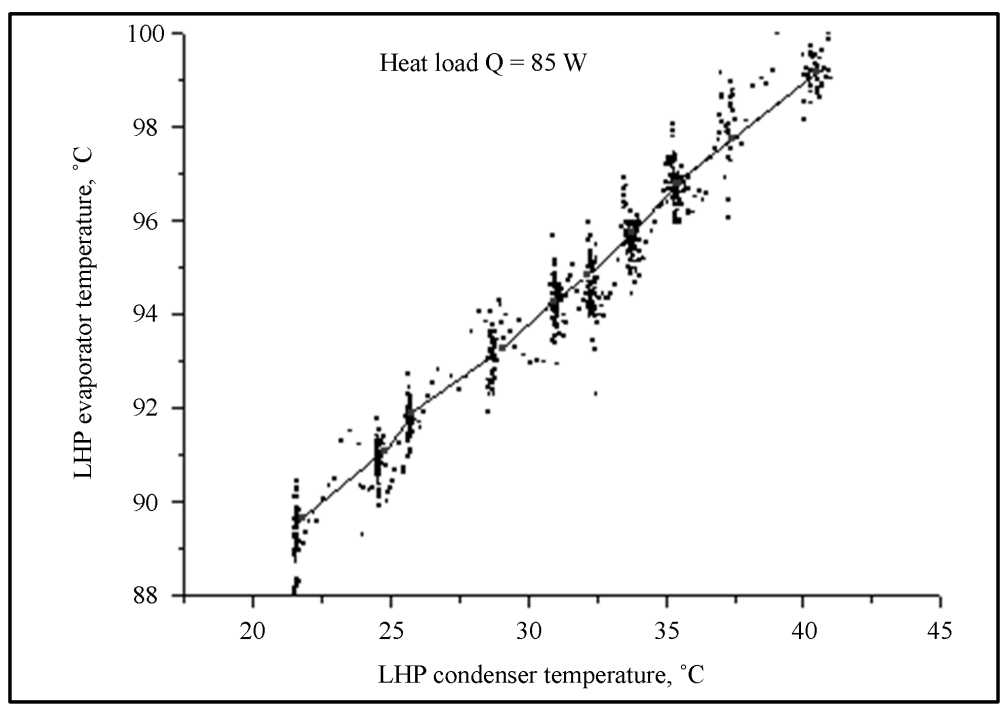

Figure 5. LHP evaporator temperature response to changes in condenser temperature for a fixed power level $(85 \mathrm{~W})$.

The thermal resistance defined as the temperature difference between LHP evaporator and condenser (estimated from Figure 5) and divided by the heat load is between 0.7 and $0.8^{\circ} \mathrm{C} / \mathrm{W}$. This range of thermal resistance is in line with the reported values for LHP in the literature [25].

\section{Conclusions}

This paper presents some preliminary works carried out recently on a low-cost LHP design. The evaporator has been manufactured using only longitudinal grooves. The wick sintering has been carried out inside the metal jacket avoiding manufacturing and assembling issues typical of conventional LHP manufacturing. The only potential limitation of the proposed design is the absence of circumferential grooves which typically allow for vapour to be distributed uniformly around the circumference of the evaporator when heat is only applied to a sector of the circumference.

The preliminary thermal tests of the proposed low-cost LHP demonstrate good time response and fairly steady temperatures at power ramp-up and -down, power cycling and variation of condenser temperature.

More tests such as low power and high power endurance, and minimum power level at start-up should be performed to gain further confidence in this design as an alternative low-cost solution suitable for those applications which do not require very demanding thermal performance from a LHP.

\section{Acknowledgements}

The author would like to thank Dr. Leonid Vasiliev Jr. for performing most of the experimental tests.

\section{References}

[1] Maidanik, Y.F., Vershinin, S., Kholodov, V. and Dolggirev, J. (1985) Heat Transfer Apparatus. US Patent No. 4515209.

[2] Delil, A.M., Maydanik, Yu.F. and Gernard, C. (2003) Development of Different Novel Loop Heat Pipes within the ISTC-1360 Project. SAE Paper No. 2003-01-2383.

[3] Swanson, D.T. (2004) Thermal Control Technologies for Complex Spacecraft Systems. Proceedings of 13th International Heat Pipe Conference, Shanghai, 21-25 September 2004, China Astronautic Publishing House, Beijing.

[4] Hoang, T.T., Cummings, S.M., Baldauff, R.W. and Brown, M.A. (2002) Advanced Loop Heat Pipes for Spacecraft Central Thermal Bus Concept. 12th International Heat Transfer Conference, Grenoble, August 2002.

[5] Goncharov, A.K., Barantsevich, V.L. and Orlov, A.A. (2003) Experience of Development of Heat Pipes Applied in Russian Spacecrafts. Proceedings of Fifth Minsk International Seminar Heat Pipes, Heat Pumps, Refrigerators, Minsk, 8-11 September 2003.

[6] Riehl, R.R. and Dutra, T. (2005) Development of an Experimental Loop Heat Pipe for Application in Future Space 
Missions. Applied Thermal Engineering, 25, 101-112. http://dx.doi.org/10.1016/j.applthermaleng.2004.05.010

[7] Semenov, S.Y., Cho, W.L. and Jensen, S.M. (2006) High Conductance Loop Heat Pipes for Space Application. AIP Conference Proceedings, 813, 43. http://dx.doi.org/10.1063/1.2169178

[8] Mishkinis, D. and Vasiliev, L. (2004) Heat Pipe Two-Phase Loop with Capillary Pump. The Update Journal of the Heat Exchanger Design Handbook, Begell House, Redding.

[9] Vasiliev, L., Lossouarn, D., Romestant, C., Alexandre, A., Bertin, Y., Piatsiushyk, Y. and Romanenkov, V. (2009) Loop Heat Pipe for Cooling of High-Power Electronic Components. International Journal of Heat and Mass Transfer, 52, 301-308. http://dx.doi.org/10.1016/j.ijheatmasstransfer.2008.06.016

[10] Maydanik, Y.F. (2005) Loop Heat Pipes. Applied Thermal Engineering, 25, 635-657. http://dx.doi.org/10.1016/j.applthermaleng.2004.07.010

[11] Chernysheva, M.A., Vershinin, S.V. and Maydanik, Y.F. (2007) Operating Temperature and Distribution of a Working Fluid in LHP. International Journal of Heat and Mass Transfer, 50, 2704-2713. http://dx.doi.org/10.1016/j.ijheatmasstransfer.2006.11.020

[12] Cheung, K., Hoang, T.T., Ku, J. and Kaya, T. (1998) Thermal Performance and Operational Characteristics of Loop Heat Pipe (NRL LHP). International Conference on Environmental Systems, Danvers, 13-16 July 1998.

[13] Khrustalev, K. (2007) Modeling Transient Operation of Loop Heat Pipes Using Thermal Desktop. TFAWS, Cleveland, 10-13 September.

[14] Parker, M.L. (2000) Modeling of Loop Heat Pipes with Applications to Spacecraft Thermal Control. Ph.D. Thesis, University of Pennsylvania, Pennsylvania.

[15] Shukla, K.N. (2008) Thermo-Fluid Dynamics of Loop Heat Pipe Operation. International Communications in Heat and Mass Transfer, 35, 916-920. http://dx.doi.org/10.1016/j.icheatmasstransfer.2008.04.020

[16] Cullimore, B.A. (1993) Capillary Pumped Loop Application Guide. 23rd International Conference on Environmental Systems, Colorado Springs, 12-15 July 1993, SAE Paper No.932156.

[17] Nagano, H., Nagai, H., Fukuyoshi, F. and Ogawa, H. (2008) Study of Thermal Performances of a Small Loop Heat Pipe. Journal of Thermal Sciences and Technology, 3, 355-367. http://dx.doi.org/10.1299/jtst.3.355

[18] Maydanik, Y.F. (2004) Miniature Loop Heat Pipes. Proceedings of 13th International Heat Pipe Conference, Shanghai, 21-25 September 2004, China Astronautic Publishing House, Beijing.

[19] Zhang, L., Xu, J. and Xu, H. (2013) Effect of Inventory on the Heat Performance of Copper-Water Loop Heat Pipe. Experimental Thermal and Fluid Science, 44, 875-882. http://dx.doi.org/10.1016/j.expthermflusci.2012.09.030

[20] North, M.T., Sarraf, D.B., Rosenfeld, J.H., Maidanik, Y.F. and Vershinin, S. (1997) High Heat Flux Loop Heat Pipes. Sixth European Symposium on Space Environmental Control Systems, Noordwijk, 20-22 May 1997.

[21] Rosenfeld, J.H., Sarraf, D.B., Khrustalev, D.K., Wellen, P.J. and North, M.T. (1999) Loop Heat-Pipe Evaporator with Bidisperse Wick Structures. NASA Tech Briefs.

[22] Ku, J., Nagano, H., Perez, J. and Rogers, P. (2006) Thermal Performance of a Low-Cost Loop Heat Pipe. Annals of the Assembly for International Heat Transfer Conference, Begell House, Redding.

[23] Vasiliev Jr., L.L. (2007) Advanced Loop Heat Pipe Evaporator with Ceramic Nanostructured Composite of Alumina, Alumina-Silica Oxide as a Wick Structure. SAE Technical Paper 2007-01-3192.

[24] Vasiliev Jr., L.L., Marengo, M., Ferrandi, C., Zinna, S. and Maziuk, V. (2009) Advanced Design of a "Low-Cost” Loop Heat Pipe. SAE Technical Paper 2009-01-2519.

[25] Launay, S., Sartre, V. and Bonjour, J. (2007) Parametric Analysis of Loop Heat Pipe Operation: A Literature Review. International Journal of Thermal Sciences, 46, 621-636. http://dx.doi.org/10.1016/j.ijthermalsci.2006.11.007 